\title{
Management Inspiration of Adopting Positive and Negative Incentives in Class Management
}

\author{
Ping Tan \\ Department of Management, Engineering and Technical College of Chengdu, University of \\ Technology, Leshan, Sichuan 614000, P.R. China \\ teresa1403318@126.com
}

Keywords: Class management; Positive motivation; Negative motivation; Management inspiration

\begin{abstract}
Class teachers take responsibilities for daily class affairs. However, they often encounter some tough things in the practice of class management. Coping with the troubles is related to class unity and the image of class teachers. There are some students who make troubles for class teachers and they would influence class atmosphere. It is appropriate to adopt correct measures to manage them. Positive motivation and negative motivation which are quite different ways should be adopted to motivate students' behaviors. In the practice of class management, class teachers should take positive and negative motivation based on students' behavioral features in order to motivate students to study and participate in activities and cultivate their responsibilities. The concept and characteristics of positive motivation and negative motivation were presented in this paper. Management inspiration of adopting positive and negative motivation was also concluded in the practice of class management in this paper.
\end{abstract}

\section{Introduction}

In the process of class management, class teachers must perform the duties of daily management. In addition, they may also encounter some troublesome things, and how to handle these matters is closely related to the unity of the whole class and class teacher's image. Besides, there existed some tough students who are difficult to manage in some class and they may definitely influence the class atmosphere. Therefore, appropriate measures should be taken to manage the tough students and slightly complex class matters.

Motivation can be divided into different types according to different dimensions, such as material motivation and spiritual motivation, motivation and self-motivation, positive motivation and negative motivation. As a class teacher, no matter what kind of motivation will be used, they must keep in mind that the nature of motivation is to make students take the initiative to do". The positive and negative incentives can be used to strengthen the students' behavior according to the behavioral characteristics and the acceptability of the motivating objects. Positive and negative incentives are two complementary types of incentives, which strengthen the behavior of people in different directions. Based on the concept of positive and negative incentives, the author introduced the characteristics of positive and negative incentives, and summarized the managerial implications of positive and negative incentives in class management practice.

\section{Concept of Positive Motivation and Negative Motivation}

The fundamental purpose of using positive and negative incentives is to continually motivate organizational members to move forward in organizations. Positive motivation refers to lasting and promoting the students' behaviors when they are in line with the needs of class through affirmation, support, reward and other ways. Positive motivation is the initiative motivation and its purpose is to set a good example. Positive incentive ways include: verbal praise, awarded honorary certificates, awards and grants selection (National Encouragement Scholarship and national grants are provided for the poor students excellent in character and study.), and excellent student selection. In addition, the class teacher can also develop more positive incentives according to their class conditions. Negative incentive refers to curbing those behaviors through criticism, sanctions, penalties and 
other means when they do not meet the needs of the class, in order to achieve the purpose of reducing or eliminating such behaviors. Negative incentive is passive motivation and its purpose is to punish someone as a warning to others. Negative incentives include: criticism, physical exercise such as the squat, providing compulsory service for class activities. These are quite slight punishing ways and are easily accepted by students. But if the student's behaviors violate the rules of the school, class teachers must truthfully inform the relative departments in charge of student affairs in time. Departments in charge of student affairs should make correct punishment based on investigation of facts. It must be noted that the teacher in charge should not use the penalty method which is quite popular in some corporations.

\section{Features of Positive Motivation and Negative Motivation}

Positive motivation and negative motivation have the following characteristics:

Positive Motivation Increases Interests While Negative Motivation Threatens Interests. Positive motivation definitely increases the interests of the motivated students through affirmation, support, praise, rewards and so on. But negative motivation which threatens students' interests is reflected in criticism, denial, punishment etc.

When Material Incentive such as Prize is Conducted as the Incentive Content, Positive Motivation Takes More Costs than Negative Motivation. Material incentive is not a small expenditure for class management. The sources of class funding are to obtain material reward and collect class fee when students first registered in the first semester. The amount used to encourage students is quite limited in class management. While negative incentive does not take up too much cost, it will not cause material burden to the class.

Positive Motivation is Easy to Implement, While Negative Motivation is Difficult to Implement [1]. The implementation of positive incentives can let all classmates know in class meetings, which should be promoted so as to set good examples and cultivate positive atmosphere in class. Class teacher can also motivate students in private through a variety of ways. But as for the negative incentives, class teacher needs to have a full understanding of starting causes, processes and results or potential consequences in detail after investigation. Then class teacher decides whether to implement negative incentive and what kind of negative incentives to implement.

Positive and Negative Incentives may Make Students Have Different Feelings. The positive and negative incentives may produce different psychological responses to the students in the process of implementation. Students who are motivated feel happy but students who are not motivated may feel appointed or dissatisfied, especially those who are rivalries. Students to be negatively motivated will have to bear the loss and they feel disgruntled, but this does not affect other students or have relatively small impact on them. Otherwise, Non-motivated students may learn a lesson from the punished students and do not make similar mistakes. Therefore, whether it is positive or negative incentive, the implementation must be fair, reasonable and be able to withstand the challenge.

If Positive and Negative Incentives are not Used Properly, This will bring Adverse Effects. Though positive incentives are easily carried on, this is just in theory. If class teacher didn't make it clear that why students were positively motivated, or positive incentive itself damaged the fairness, class teachers' authority would be reduced. And it's difficult to guarantee the incentive effect or finally positive motivation would be proved to be counterproductive. As to negative motivation, if class teachers haven't found the truth of the incidents or roots of problems, the implementation of negative incentives without forethought would lead to confrontation or even conflict, between class teachers and the students who were negatively motivated.

\section{The Management Inspiration of Positive Incentives in Class Management}

Following the concept of strict management to lay a good foundation in class management, class teachers should flexibly use positive ways such as affirmations, support, guidance, care, praise and 
reward to encourage students. To make positive incentives achieve good results, class teachers need to pay attention to the following three aspects.

The Contents of Positive Incentive should be Expressed Clearly and Comprehensively, and the Standard of Measurement should be Stable without Prejudice to Fairness. In class management, selection of National Encouragement Scholarship, national grants, outstanding students, outstanding cadres and outstanding graduates is one of the most difficult and important issues. Selection process should pay attention to the students' opinions, the criteria should be unified and has stability, and finally positive incentive reasons must be attached in the published list. The fair process can show that student's effort is worth it. The positively encouraged students will feel the honor and what they've won is just through fair competition without any shortcuts to go. Other students will also feel fair and they will be attributed to themselves such as lack of effort and performance being not outstanding rather than objective reasons. Thus they can redouble efforts to catch up, which is the power of positive incentive. Positive incentives can play an incentive role for both excellent students and students who lag behind temporarily. On the contrary, if the contents of positive were not clearly and comprehensively expressed, so students didn't know why these students were praised rather than others. Even some class teachers directly designated heir to get prizes or become outstanding graduates. This behavior would make students feel unfair and they would feel dissatisfied. More seriously, the wrong doings might lead to conflicts. At the same time, students would not trust their class teachers anymore and the whole class atmosphere would be worse than before.

Positive Motivation is for Students' Outstanding Performance rather than Their Hard Work. One example is represented as following: There was a student who was the most important cadre in the class. He actively took part in a variety of activities, helped the class teacher to manage the class and won many honors for class in department contests. But in the final exam of one term, his grades were medium. In a conversation with his class teacher, He talked about his future career planning and his mother's expectation. He said he was ashamed of his final exam and told the class teacher he would be so happy if he got a National Encouragement scholarship. The class teacher explained the selection criteria of National Encouragement Scholarship, encouraged him to use the standard as a measure of learning and hoped he could do better in study. After all, competition in class was rather fierce.

Positive Incentives should be Targeted for Different Students. Different students have different needs. Class teacher should be familiar with their needs so that class management work will be targeted. Therefore, the class teacher should often go to student dormitory and create more communication opportunities to know more about the situation of students. Some students are curious, creative and have desire to explore new things. They like to participate in various activities and contests to show themselves. So the class teacher may offer some help for these students such as providing advice for reference and guidance and modifying commercial planning documents for entrepreneurship contest. Others pay more attention to emotion, and once they encounter some difficulties in interpersonal relationship, class teacher should strengthen communication with them, be patient to listen to their stories, understand their emotional needs, and provide feasible suggestions to help them cope with the difficulties according to their own life experience.

\section{The Management Inspiration of Negative Incentives in Class Management}

Negative Incentive is an Effective Management Measure. It's hard to imagine what a class will go without negative incentives. There was a class teacher who used negative incentives in the process of class management, with particular emphasis on the word "credit and trust". In her opinion, "credit" is not only commitment between different people, but also closely related to their reputation and image in the eyes of class teacher. Students who have violated the rules of the school would be negatively motivated depending on the severity of violation. For example, for students being absent from school, they won't be allowed to ask for leave during the term, unless a major change happened in the student's family or a serious illness occurred to the student or family 
members. Students learn to value their own credit and bear the consequences through the strict requirements.

Cultivate Students' Devoting Spirit and Sense of Responsibility. Today, 90s is still the majority on campus in universities or colleges. Two or three years later, students born in 2000 will quickly enter university or college. From the perspective of cultivating students of $90 \mathrm{~s}$, education is further becoming a problem, because these students are the whole hope of their family and their family has put a lot of energies on them. They've received too many concerns and love from the whole family. Some of them have become unconventional, maverick and egotistical. What's more, the whole society atmosphere also has some side effects on them. With the popularity of computers and intelligent mobile phones, these electronic products have occupied their too much time, playing games has become a main task in class, let alone to say their pastime entertainment for many college students. Most of them did not have any bad sufferings and setbacks, so their poor psychological endurance has to let people and family worry about. Some college students who account for a considerable proportion of the whole college students still do not love school and learning, violate rules and regulations and are not willing to take responsibility. These bad behaviors have caused a lot of troubles to class management. For these students, the class teacher should not only do ideological work as a guide, but also give students chances to experience, feel, or even suffer setbacks in practice. Only when they realize that they must be practical, hard-working, willing to devote and take responsibility, and no longer complain, they can adapt themselves to the society in the future. Andrew Carnegie once said, "you can't push anyone up the ladder unless he climbs up."

Negative Incentive's Purpose is to Avoid Wrong Doings Become Serious at the Outset. In the class there are always some students who do not comply with the relevant regulations. in violation of the rules of the school. If a student violated regulations for the first time without negative incentive, which would damage the authority of disciplines and rules, and finally college rules and disciplines would be challenged by more and more students. Therefore, class teachers should not convey information such as "never again" when they have communications with students. If there are violations of disciplines, students must bear the corresponding responsibility.

Do a Good Job of Students' Ideological Work. Negative incentives will bring negative feelings to the students who have been negatively motivated. It may undermine their self-esteem. Some students cannot face negative incentives correctly, or they even become more negative than before. Therefore, the implementation of negative incentive should be based on a premise - to do ideological work of students. Class teachers must control their emotions and mustn't lose temper when they communicate with students. What they should do is to understand the truth of the incident and do not make any punishing decisions before they make a detailed inquiry. Then they should point out the mistakes the students have already made and the consequences. Criticism and punishment should not be made in a public occasion.

\section{References}

[1] X.Q. Chen and S. Jian: Journal of China Agricultural University, vol. 65(2006) No.4, p. 52-56. 